\title{
NUMERICAL INVESTIGATION IN DETECTION OF PRESTRESS LOSSES IN PRESTRESSED CONCRETE SLAB BY MODAL ANALYSIS
}

\author{
Andrejs Kovalovs, Pavel Akishin, Sandris Ruchevskis \\ Institute of Materials and Structures, Riga Technical University, Latvia \\ andrejs.kovalovs@rtu.lv
}

\begin{abstract}
The paper presents a non-destructive method to detect prestress loss in prestressed hollow core slabs using a few modal frequencies. Loss of prestress is investigated by the 3D finite element model, using ANSYS software. A numerical model is used to estimate the percentage change in modal frequencies of prestressed slabs under various initial stresses induced in the tendon. Applicability and effectiveness of the proposed method are investigated by using various span lengths of slabs and elastic modulus of concrete. The parametric study shows that the minimal length of slab and maximal elastic modulus has the smallest influence on the percentage change in the modal frequencies. The results of this investigation thus indicate that proposed method can potentially be used to identify the initial stress reduction in concrete structures with minimal elastic modulus of concrete and the largest length of span.
\end{abstract}

Keywords: prestress, concrete slab, frequencies, ANSYS, FEM.

\section{Introduction}

Today prestressed concrete elements are widely used in many civil constructions for commercial and industrial buildings. Prestressing force in tendons is used to reduce the cross-section and deflections of prestressed concrete structures. However, the prestressing force decreases over time due to time dependent deformation of concrete, steel relaxation in strands, creep of concrete and other factors. Also it is known that the loss of the prestress force occurs due to damage or severing of prestress strands. In this case, a prestressed concrete structure is considered as irreparable as it is seriously damaged on the condition of the prestressing strands [1].

These losses of the prestressing force lead to the safety problem of prestressed concrete structures. In this case, it is very important to estimate the prestress loss, because the prestressed concrete must keep effective prestressing force during the service life of the concrete structure.

One of the methods to detect a possible loss of the prestressing force in prestressed concrete structures is implementation of dynamic monitoring. Loss of prestress can change the stiffness of the structure, which causes changes of the dynamic parameters. It is possible to identify loss of prestress by comparing the frequencies of the reference structures and the frequencies of the structure with reduced prestressing forces.

In recent years, development of damage detection techniques based on modal parameters was extensively studied. It is possible to identify damage of a structure by comparing the typical dynamic properties of the damaged and undamaged structure. This method is being widely used, because it is very simple in use. Many algorithms for damage detection were developed by many researchers over the three decades in the field of vibration based damage detection $[2 ; 3]$.

However, there are many disagreements about how the prestressing force in tendon affects the modal frequencies of prestressed concrete structures:

1. The modal frequency decreases with increasing the prestressing force $[4 ; 5]$.

2. The modal frequency increases with increasing the prestressing force $[6 ; 7]$.

3. The prestressing force is unaffected by the modal frequency [8;9].

Law, S. S. and Lu [4] studied the time-domain response of a prestressed Euler-Bernoulli beam

Later, Breccolotti [10] analysed different source in literature connected with problem of prestressed concrete beam. From the preparatory work done by Brecoloti, it was concluded that increase of the modal frequency and prestressing force is true for low values of the prestressing level (5-10\% of the ultimate compression strength of the section). In the opposite case, the frequency decreases, when the prestressing force has a higher value.

The aim of this study is to investigate the percentage change of modal frequency in prestressed concrete hollow core slabs under various values of prestressing forces that simulate the damage level in the strand. The modal frequencies are numerically calculated by the $3 \mathrm{D}$ finite element method 
(FEM), using ANSYS software. The prestressing force in the strand is applied as an initial stress. The effectiveness of using percentage changes in modal frequencies as indicators of the loss of prestress is studied. Applicability and effectiveness of the proposed method are investigated by using various span lengths of slabs and elastic modulus of concrete.

\section{Numerical model and properties}

For numerical research, a typically prestressed hollow core slab that is generally used for flooring was chosen. The cross-section dimensions are shown in Fig. 1. The slab is $1200 \mathrm{~mm}$ width with standard thicknesses $200 \mathrm{~mm}$ and the span length is $11000 \mathrm{~mm}$. The slab is prestressed by seven-wire stress-relieved strands of $15 \mathrm{~mm}$ diameter located $35 \mathrm{~mm}$ from the soffit and built by extrusion. The properties of the prestressed slab are outlained in Table 1 [9].

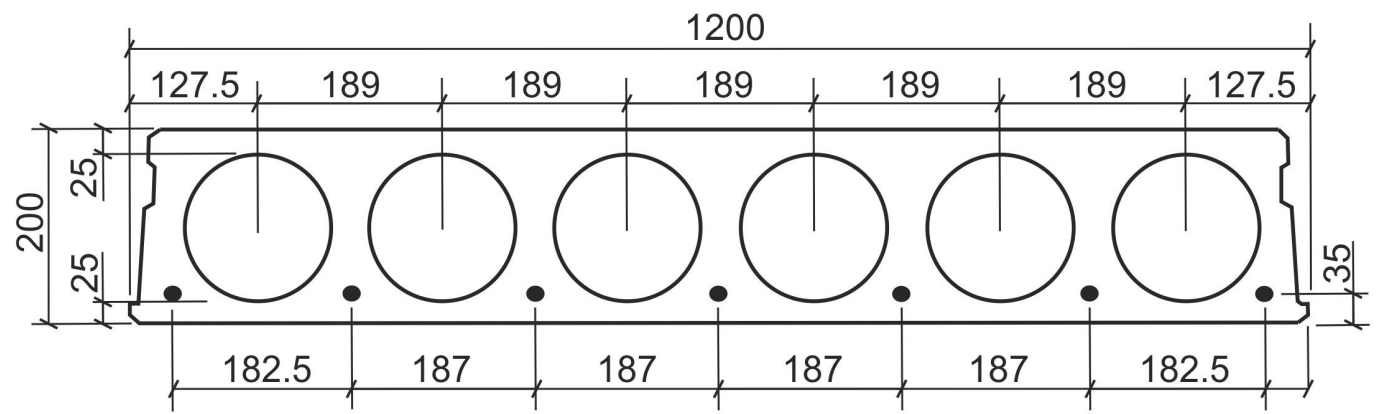

Fig. 1. Cross-section of prestressed hollow core slab (Dimensions in mm)

Table 1

Material properties of concrete and steel strands

\begin{tabular}{|c|c|c|c|c|}
\hline & Symbol & Concrete & Steel strands & Unit \\
\hline Young's modulus & $E$ & 27.0 & 180 & $\mathrm{GPa}$ \\
\hline Poisson's ratio & $v$ & 0.2 & 0.3 & - \\
\hline Density & $\rho$ & 2400 & 7850 & $\mathrm{~kg} \cdot \mathrm{m}^{-3}$ \\
\hline
\end{tabular}

A three-dimensional (3D) finite element model of the prestressed hollow core slab is simulated using commercial finite element software ANSYS16.0. Solid65 and Link180 elements are selected to represent concrete and 3D truss element, respectively. Solid65 element has three-dimensional concrete elements with eight nodes and three translational degrees of freedom at each node. The most important aspect of this element is treatment of nonlinear material properties. This element is capable of plastic deformation, cracking in three orthogonal directions, and crushing. Link180 is suitable for modeling the prestressing strands in the slab. This 3D spar element is a uniaxial tension-compression element with three translational degrees of freedom at each node and translations in the nodal $x, y$, and $z$ directions. In the finite element model, Link180 element for the steel reinforcing strand is connected between the nodes of each adjacent concrete solid element and has the same length as the concrete elements along the span length.

The prestressed concrete slab is simply supported at the two shortest opposite edges. The bottom nodes at one edge are restricted in the direction along the span length and height of the slab. In the second edge, the bottom nodes are restricted only in the span length direction. The boundary conditions of the real structure show other frequency values. It is assumed that percentage change of these values will be considered of the same level as for the present boundary conditions.

Some model simplifications are done, namely the side walls of the slab are aligned. This gives the possibility to decrease the dimension of the finite element model. Fig. 2 shows the fragment of the finite element mesh.

The procedure for performing a modal analysis of the prestressed concrete slab in finite element program ANSYS is concerned by the effect of initial stress on the dynamic response of the concrete structure and includes structural and modal analysis. In the first step, a nonlinear static solution with a prestress effect is performed. In the second step, the resulting stress field is used in a modal analysis. 
The stresses are applied using the "initial state" (INISTATE) command. This command has the ability to apply the prestressing force to the strand as an initial stress. The tension in the strand is transferred as compression to the concrete structure through the perfect bond between concrete and embedded link elements. The stresses are applied to all selected elements of the strands and the resulting stress and strain fields are determined. The self-weight of the prestressed slab is included in the finite element model and taken into account by providing the value of acceleration due to gravity $\left(9.81 \mathrm{~m} \cdot \mathrm{s}^{-2}\right)$.

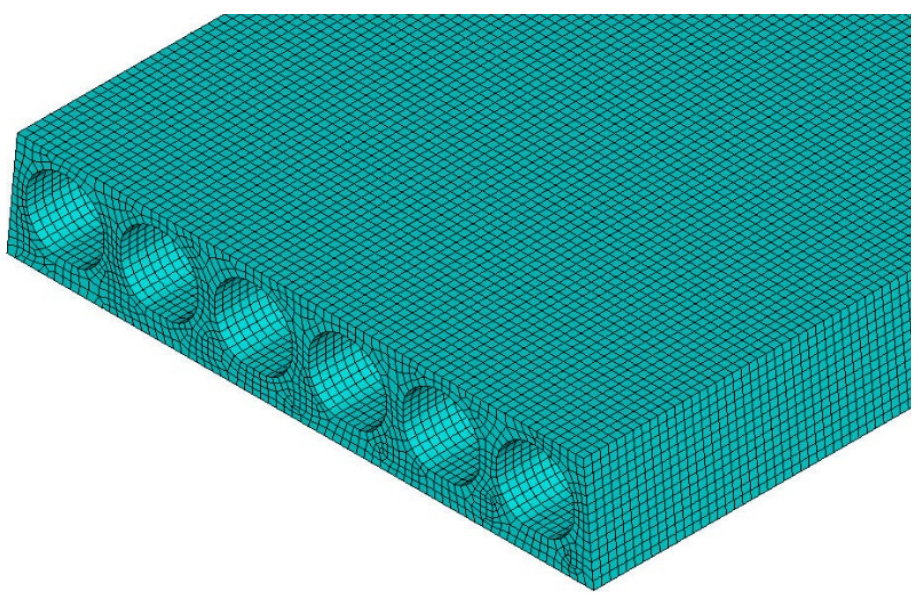

Fig. 2. Fragment of finite element model

\section{Results and discussion}

In the first stage, a numerical model of the slab is calculated to compare modal bending frequencies and to study the effectiveness of the proposed method for calculation of the modal frequency percentage change and investigation in the effect of prestressing on modal frequencies. Loss of prestress is modeled by decreasing of the initial stress in the prestressed strand located in the center of the slabs. The ultimate tensile strength of the steel strands $f_{s}$ is $1500 \mathrm{MPa}$. The jacking stress is $80 \%$ of the ultimate tensile strength and equal to $1200 \mathrm{MPa}$. The values of the initial stress in the strand are varied from $0 \mathrm{MPa}$ to $1200 \mathrm{MPa}$, which corresponds to the beginning of damage and loss of prestress finally, respectively. The strand is prestressed with 7 discrete levels to investigate the variation of the modal frequencies. The results of these investigations are listed in Table 2, where the modal frequencies of the 1 st and 2 nd vertical bending modes are depicted, respectively. First two bending mode shapes of the prestressed concrete slab are shown in Fig.4.

Table 2

Modal frequencies

\begin{tabular}{|c|c|c|c|c|}
\hline $\begin{array}{c}\text { Initial stress, } \\
\mathbf{M P a}\end{array}$ & $\begin{array}{c}\text { Modal } \\
\text { frequencies of } \mathbf{1}^{\text {st }} \\
\text { bending, Hz }\end{array}$ & $\begin{array}{c}\text { Modal frequency } \\
\text { percentage } \\
\text { change, \% }\end{array}$ & $\begin{array}{c}\text { Modal } \\
\text { frequencies of 2 } \\
\text { bending, } \mathbf{~ H z}^{\text {nd }}\end{array}$ & $\begin{array}{c}\text { Modal frequency } \\
\text { percentage } \\
\text { change, \% }\end{array}$ \\
\hline 1200 & 1.25 & 0 & 10.82 & 0 \\
\hline 1000 & 1.33 & 6.0 & 10.85 & 0.6 \\
\hline 800 & 1.40 & 10.6 & 10.89 & 0.6 \\
\hline 600 & 1.46 & 14.4 & 10.92 & 0.9 \\
\hline 400 & 1.52 & 18.0 & 10.96 & 1.2 \\
\hline 200 & 1.58 & 21.1 & 10.99 & 1.5 \\
\hline 0 & 1.64 & 23.8 & 11.02 & 1.8 \\
\hline
\end{tabular}

The modal frequency percentage change is calculated using the ratio of the corresponding modal frequencies for the prestressed concrete slab with reference initial stress $1200 \mathrm{MPa}$ and with reduced initial stress (1):

$$
\Delta_{f}=\left|\frac{f_{i}-f_{1200}}{f_{i}}\right| \cdot 100,
$$


where $f_{1200}$ - modal frequency of prestressed concrete slab with initial stress $1200 \mathrm{MPa}, \mathrm{Hz}$; $f_{i}$ - modal frequency of prestressed concrete slab with reduced initial stress, Hz.
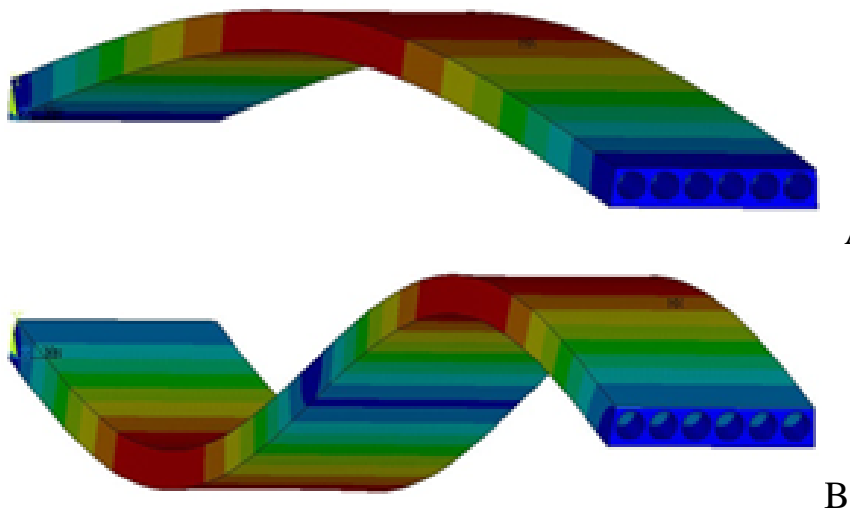

A

B

Fig. 3. Mode shapes: A $-1^{\text {st }}$ bending mode shape, $\mathrm{B}-2^{\text {nd }}$ bending mode shape

From the results given in Table 2 it is seen that modal frequencies increase with decreasing the initial stress. The frequency percentage changes differ significantly depending on the mode shapes. Percentage change for the second bending mode does not exceed $1.8 \%$, while the percentage change obtained in the first bending mode gives a comparably larger value $-23.8 \%$. Further, the values of the first bending mode shape are used for calculation of the frequency percentage change.

In the next stage, the numerical model of prestressed concrete slabs with different length of spans and elastic modulus are introduced and similar computation procedure is used to obtain the modal frequency to calculate the percentage changes. The span length of slabs is varied, starting with $8 \mathrm{~m}$ up to $11 \mathrm{~m}$. The elastic modulus is taken additionally as $29.0 \mathrm{MPa}$ and $31 \mathrm{MPa}$, respectively. The result of the frequency percentage changes obtained for various span lengths of slabs and elastic moduli from numerical simulation are plotted in Fig. 4-6.

The data of Fig. 4 demonstrate a percentage changing of the frequency, when the elastic modulus of concrete is $27 \mathrm{GPa}$. The percentage changes of the frequency begin to grow with reduced initial stress in the strand. The smallest values of percentage changing correspond to the shortest length of the span. The data of Fig. 5 and 6 demonstrate a percentage changing of the frequency, when the elastic modulus of concrete is $29 \mathrm{GPa}$ and $31 \mathrm{GPa}$, respectively. As shown, the percentage changes are decreased, when the elastic modulus begins to grow. For example, percentage change of the slab with $11 \mathrm{~m}$ length, when the elastic modulus of concrete is $31 \mathrm{GPa}$, does not exceed $14.9 \%$, while the percentage change obtained for the slab with the elastic modulus $27 \mathrm{GPa}$, gives a comparably larger value $-23.8 \%$. Difference in the percentage change achieves almost $9 \%$. It is seen that the modal frequency percentage change is dependent on the span length of slabs and elastic modulus.

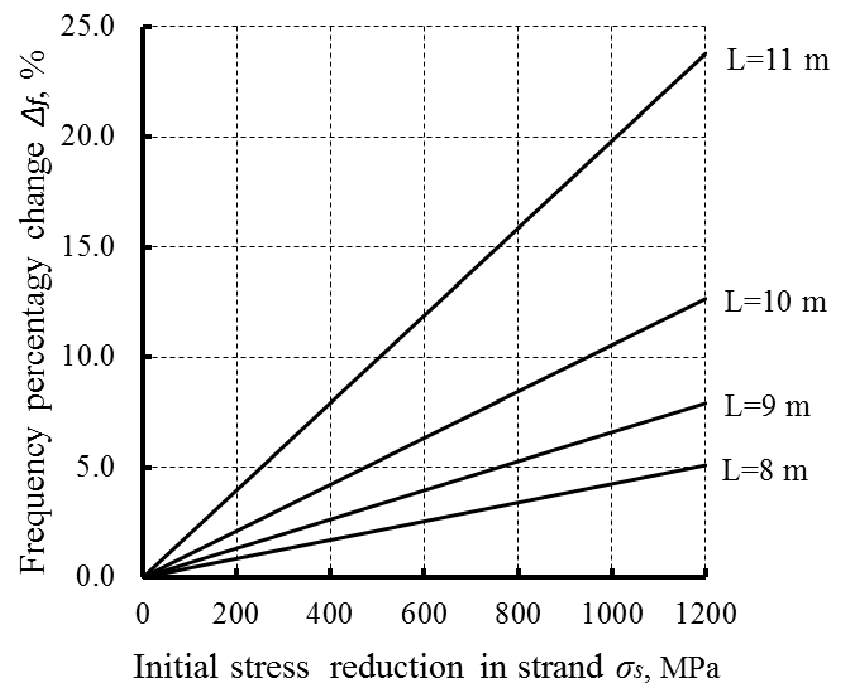

Fig. 4. Frequencies percentage change when $E_{c}=27 \mathrm{GPa}$ 


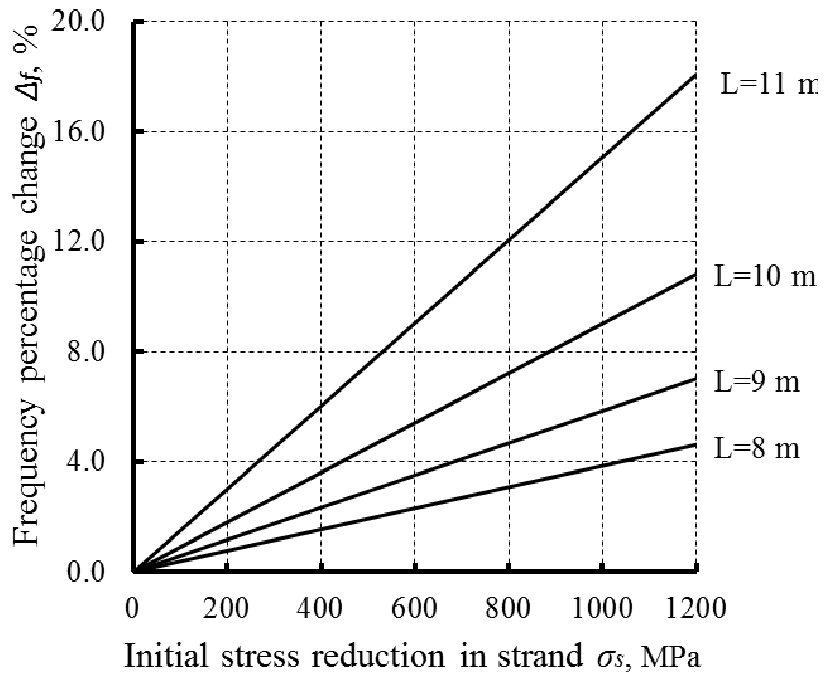

Fig. 5. Frequencies percentage change when $E_{c}=29 \mathrm{GPa}$

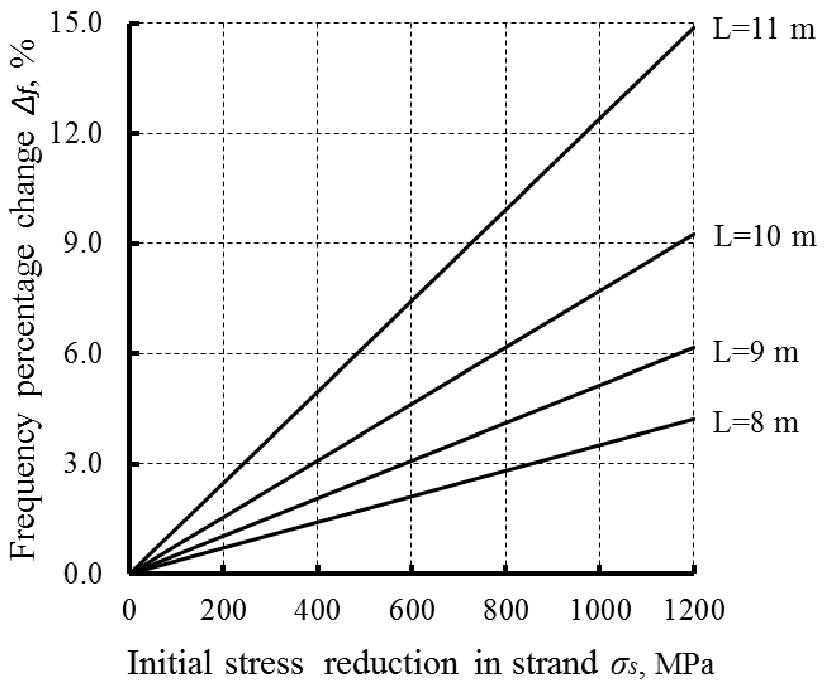

Fig. 6. Frequencies percentage change when $E_{c}=31 \mathrm{GPa}$

It is assumed that the frequency percentage change must exceed $5 \%$ for detecting loss of prestress. If the difference does not exceed $5 \%$, detection is impossible. This is because modal frequencies are small at each level of loading. Table 3 shows the calculated reduction of the initial stress in the strand required for loss of prestress detection with the frequency percentage change of $5 \%$. The slab with $8 \mathrm{~m}$ of length had the smallest frequency percentage change in comparison with the other span lengths (less than $5 \%$ ) and it is not included in Table 3. It is seen that the prestressed concrete slab with minimal elastic modulus $27 \mathrm{GPa}$ has more capability to detect loss of prestress in the strand than the prestressed concrete slab with the greatest elastic modulus $31 \mathrm{GPa}$.

Table 3

Minimal detectable reduction of initial stress in strand MPa

\begin{tabular}{|c|c|c|c|}
\hline \multirow{2}{*}{$\begin{array}{c}\text { Span of prestressed } \\
\text { concrete slab, m }\end{array}$} & \multicolumn{3}{|c|}{ Elastic modulus } \\
\cline { 2 - 4 } & $\mathbf{2 7}$ GPa & 29 GPa & 31 GPa \\
\hline 11 & 252 & 332 & 403 \\
\hline 10 & 474 & 554 & 649 \\
\hline 9 & 759 & 855 & 974 \\
\hline
\end{tabular}

\section{Conclusions}

Based on the discussion of the results obtained by numerical simulation, the following conclusions can be made: 
4. 3D finite element models of prestressed concrete hollow core slabs have been built according to the producer's requirements. The span length of the slabs is varied, starting with $8 \mathrm{~m}$ up to $11 \mathrm{~m}$, and the elastic modulus is taken as 27.0 MPa, 29.0 MPa and 31 MPa.

5. Research in the influence of the span length of the prestressed concrete hollow core slab and elastic modulus of concrete is carried out with the purpose to study the effectiveness of the proposed method. The parametric study has shown that the minimal length of the slab $8 \mathrm{~m}$ and the maximal elastic modulus $31 \mathrm{GPa}$ have the smallest influence on the percentage change in modal frequencies $(4.2 \%)$. The largest influence on the percentage change is demonstrated by the concrete slab with the maximal length of the slab $11 \mathrm{~m}$ and the minimal elastic modulus $27 \mathrm{MPa}$ $(23.8 \%)$.

6. If assumed that the frequency percentage change must exceed $5 \%$ for detecting loss of prestress, the prestressed concrete slab with the minimal elastic modulus $27 \mathrm{GPa}$ has more capability to detect loss of prestress in the strand than the prestressed concrete slab with the greatest elastic modulus $31 \mathrm{GPa}: 252 \mathrm{MPa}$, when the length of the slab is $11 \mathrm{~m}$, and $759 \mathrm{MPa}$, when the length of the slab is $9 \mathrm{~m}$.

7. The numerical results of this investigation demonstrate the effectiveness to detect reduction of the initial stress in strands by using the modal frequency percentage change.

\section{References}

[1] Civjan S.A., Jirsa J.O., Carrasquillo R.L. and Fowler D.W. Method to evaluate remaining prestress indamaged prestressed bridge girders. Research Report, 1995, 1370-2

[2] Doebling S.W., Farrar C.R., Prim M.B. A summary review of vibration-based damage identification methods. Shock and Vibration Digest, Vol. 30, 1998, pp. 91-105.

[3] Salawu O. Detection of structural damage through changes in frequency: A review. Engineering Structures, Vol. 19(9), 1997, pp. 718-723.

[4] Law S. S. and Lu Z. R. Time domain response of a prestressed beam and prestress identification. Journal of Sound and Vibration, Vol. 288, 2005, pp. 1011-1025.

[5] Miyamoto A., Tei K., Nakamura H. and Bull J.W. Behavior of prestressed beam strengthed with external tendons. Journal of Structural Engineering, Vol. 126(9), 2000, pp. 1033-1044

[6] Jang J., Lee H., Hwang K., Song, Y. A sensitivity analysis of the key parameters for the prediction of the prestress force on bonded tendons. Nuclear Engineering and Technology, Vol. 42(3), 2010, pp. 319-328.

[7] Lu Z., and Law S. Identification of prestress force from measured structural responses. Mechanical Systems and Signal Processing, 20(8), 2006, pp.2186-2199.

[8] Noble D., Nogal M., O'Connor A., Pakrashi V. The effect of prestress force magnitude on the natural bending frequencies of prestressed concrete structures. Proceedings of the 23rd Australasian Conference on the Mechanics of Structures and Materials (ACMSM23), Byron Bay, Australia, 2014. P. 7.

[9] Hamed E. and Frostig Y. Natural frequencies of bonded and unbonded prestressed beamsprestress force effects. Journal of Sound and Vibration, Vol. 295(1-2), 2006, pp. 28-39.

[10] Breccolotti M. On the Evaluation of Prestress Loss in PRC Beams by Means of Dynamic Techniques. International Journal of Concrete Structures and Materials. 2018, DOI 10.1186/s40069-018-0237-8, P.15.

[11] SNiP 2.03.01-84 Reference manual. 